\title{
Can Celebrity Endorsements Affect Political Outcomes? Evidence from the 2008 US Democratic Presidential Primary
}

\author{
Craig Garthwaite \\ Northwestern University \\ Timothy J. Moore \\ University of Maryland
}

Identifying the effects of political endorsements has historically been difficult. Before the 2008 Democratic presidential primary, Barack Obama was endorsed by talk show host Oprah Winfrey. In this article, we assess the impact of this endorsement using, as measures of Winfrey's influence, subscriptions to her magazine and sales of books she recommends. We find that her endorsement increased Obama's votes and financial contributions, and also increased overall voter turnout. No connection is found between the measures of Oprah's influence and previous elections, nor with underlying political preferences. Our results suggest that Winfrey's endorsement was responsible for approximately 1 million additional votes for Obama. (JEL D7, D72)

\section{Introduction}

Political endorsements have a long and rich history in American politics. Endorsements by politicians and interest groups, such as labor unions and business organizations, date back to the early 20th century. Celebrity endorsements have a tradition nearly as long. Historians trace the role of celebrities in politics to the 1920 presidential campaign of Warren Harding, who was endorsed by film stars such as Al Jolson and Mary Pickford (Morello 2001). Many presidential campaigns since have involved celebrities. For example, in 1960 John F. Kennedy was supported by "Rat Pack" members such as Sammy Davis Jr. and Dean Martin, and Ronald Reagan received support from many celebrities, including Frank Sinatra (Adamowski 2004; Jolson-Colburn 2007).

We are grateful to Bill Evans for his advice and comments. We also thank Kerwin Charles, Allan Drazen, Mark Duggan, Kyle Handley, Judy Hellerstein, Dan Hungerman, Melissa Kearney, Brian Knight, Sebastian Miller, John Shea, and the seminar participants at the University of Maryland for useful suggestions. For access to their data, we thank the Audit Bureau of Circulations, Mediamark Research and Intelligence, and Jim King at Nielsen BookScan. All errors remain our own.

The Journal of Law, Economics, \& Organization, Vol. 29, No. 2 doi:10.1093/jleo/ewr031

Advance Access publication February 10, 2012

(c) The Author 2012. Published by Oxford University Press on behalf of Yale University.

All rights reserved. For Permissions, please email: journals.permissions@oup.com 
Political candidates court those who may be willing to make endorsements, send out press releases when endorsements occur, and often arrange their campaign schedules to appear with endorsers. Although these actions demonstrate a belief by candidates that endorsements are important, they are often accompanied by media commentary that such endorsements have little or no effect on vote share. A recent, frequently cited example of the lack of an effect was Hillary Clinton defeating Barack Obama in the 2008 Massachusetts Democratic Primary. In describing that election, Gary Younge, a columnist for The Nation, wrote: "[i]n this election cycle endorsements do not seem to have made the slightest difference. Obama bagged support from Massachusetts Senators Ted Kennedy and John Kerry and Governor Deval Patrick, only to lose the state by $15 \%$ " (Younge 2008).

Few academic studies have documented a clear link (or lack thereof) between endorsements and voter behavior (Stratmann 2005). Attempts to estimate such a connection are hampered by the difficulty of finding a measure of an endorsement's impact that is uncorrelated with the underlying level of support for the candidate. Potential measures, such as interest group membership or the political support for endorsing politicians, are affected by political preferences that are likely to be correlated with ex ante support for the eventual endorsee.

Barack Obama announced he was running for election as president of the United States in February 2007. Three months later, he was endorsed by the talk show host Oprah Winfrey. Winfrey's endorsement of Obama provides a rare opportunity to examine the effect of an endorsement on political outcomes, primarily because there are geographically varying indicators of her popularity and influence that should be unrelated to political factors. She has a history of endorsing commercial goods and creating products whose attractiveness to consumers is intimately connected to the degree to which they like her. Winfrey's ability to influence the actions of her supporters is impressive. As an example, Figure 1 contains sales figures for two books included in her book club: Anna Karenina by Leo Tolstoy and Love in the Time of Cholera by Gabriel Garcia Marquez. The sales of both books increased over a 100-fold immediately after their selection. Polling evidence suggests that such effects on consumer decisions may translate to politics, with $23 \%$ of Democrats saying that Winfrey's endorsement would make them more likely to vote for Obama (Pew Research Center 2007). In this analysis, we use geographic variation in the sales of books included in "Oprah's Book Club" as a measure of the expected efficacy of the endorsement. Winfrey also produces $O$, The Oprah Magazine (hereafter "Oprah Magazine"), which featured her on the cover of every issue until April 2009 and is intimately connected with her brand. We also use county-level variation in Oprah Magazine subscriptions as a measure of Winfrey's popularity. ${ }^{1}$

1. Another potential measure of Oprah's commercial success is television ratings. We were unable to gain access to Nielsen television ratings. Even if the data were available, the sample size would be relatively small and unlikely to demonstrably improve the analysis. In addition, television viewing is a relatively passive activity, compared with buying books, subscribing to magazines, and voting. 


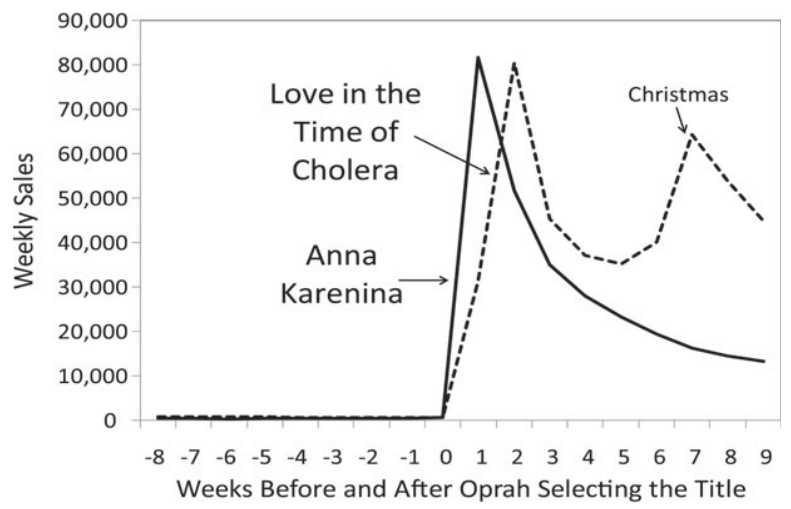

Figure 1. Effect on Sales of Oprah Recommending Anna Karenina and Love in the Time of Cholera.

Other factors also facilitate analyzing the effects of this endorsement. Despite having a nationally broadcast television show since 1986, Winfrey had never before endorsed a candidate for elective office. Therefore, indicators of her influence prior to her endorsement of Obama should not be directly contaminated by voters' political preferences or a connection to past political candidates. Furthermore, Oprah is regarded as one of the most influential public figures in the United States. If a celebrity endorsement is ever going to have an empirically identifiable influence, then it is likely to be hers. Finally, the lengthy 2008 Democratic Primary process created a large sample of elections for analysis.

We estimate the county-level relationship between Obama's vote share and per capita subscriptions to Oprah Magazine, controlling for factors such as race, gender, and income. Our results suggest that Winfrey's endorsement of Obama prior to the 2008 Democratic presidential primary generated a statistically and qualitatively significant increase in the number of votes Obama received. Similarly sized effects are found using the sales of books included in Oprah's Book Club. We consider whether these results are affected by omitted variables by estimating three models with political outcomes that should be unrelated to Oprah Magazine's per capita circulation: (1) votes from the 2004 Illinois Democratic primary that Barack Obama contested, (2) an index of the "liberalness" of voting by House of Representatives' members, and (3) the Democratic vote share in the 2002, 2004, and 2006 US Senate elections. We also estimate a model using the 2008 Democratic primary data that include circulation figures for magazine titles that have similar readers as Oprah Magazine but for which there should be no relationship with support for Obama. We do not find an underlying relationship between the variables of interest contained in these four falsification exercises, apart from the possibility that the readers of magazines with a similar demographic base to Oprah Magazine - absent the endorsement - may have been less likely to vote for Obama than for other candidates, such as Hillary Clinton. We also consider 
financial contributions to Obama's campaign before and after the endorsement. We find that, in the time period after the endorsement, contributions increased more in counties where Oprah Magazine had high per capita sales than in other counties. The consistent pattern across the main results, falsification tests, and financial contributions analysis suggests that our results are due to the endorsement rather than the omitted variables.

Our results suggest that a $10 \%$ change in the county-level circulation of Oprah Magazine is associated with an increased vote share for Obama of approximately 0.34 percentage points in states with primary elections. Similar exercises suggest that voter turnout also increased as a result of the endorsement, and we estimate that a $10 \%$ change in circulation is also associated with a 0.06 percentage point increase in turnout in these states. In total, we estimate that the endorsement was responsible for 1,015,559 votes for Obama. The 95\% confidence interval around this estimate is higher than the difference in votes between Obama and Hillary Clinton in our sample. This suggests that, in our sample, Winfrey's endorsement was responsible for the difference in the popular vote received by the two leading candidates in this election.

\subsection{Political Endorsements}

The economics and political science literature addressing the effect of endorsements on political outcomes is primarily theoretical and has mainly focused on endorsements by interest groups. In these models, uninformed individuals decide whom to vote for using political cues from interest groups and other sources, such as social groups, political advertising, and the media.

Grofman and Norrander (1990) develop a model where endorsements serve as signals to voters about the underlying ideological and policy preferences of candidates and thereby affect electoral outcomes. Grossman and Helpman (1999) consider the role of endorsements when both interest group leaders and political candidates seeking their endorsement behave strategically. They develop a model where voters are not fully informed about a policy issue and candidates are willing to shift their position on this issue in order to maximize their votes. Wittman (2009) shows that, even in such circumstances, voters can use the endorsement of interest groups to infer the relative positions of candidates and vote appropriately.

A recent development has been to consider how interest groups can convey information about a candidate's quality or "valence," which is determined by personal characteristics and is orthogonal to a candidate's policy positions. Prat (2002) and Coate (2004) consider the ability of interest groups to convey information about a candidate's quality through costly advertising, whereas Wittman (2007) considers how interest group endorsements can cheaply convey information about quality. In a similar way, endorsements by celebrities may provide information shortcuts that can signal the quality of a candidate to voters at little or no cost.

Empirically estimating the effect of endorsements has been difficult. Rapoport et al. (1991) estimate the effect of endorsements by labor unions and interest 
groups on voting behavior during the 1984 Democratic presidential caucuses in Virginia, Michigan, and Iowa by looking at how union and interest group members voted. The ex ante support for candidates was not controlled for, however, meaning the effect of the endorsements could not be separated from members' underlying preferences for candidates. McDermott (2006) attempts to overcome this problem by using survey data on how respondents say they would react to labor union endorsements, although it is not certain that their voting behavior would match their responses. Chiang and Knight (2011) use differences in the timing of newspaper endorsements to assess their effects on voter attitudes. They find that readership influences which candidate a newspaper endorses and that an endorsement has an identifiable influence on whom readers vote for when it is a departure from a newspaper's expected endorsement policy. Finally, Arceneaux and Kolodny (2009) conduct a field experiment where both Democrat and Republican voters were contacted about a liberal group's endorsement of two Democratic statehouse candidates in Pennsylvania. They find that this information decreased Republican votes for these candidates, showing that endorsements can have negative effects on electoral outcomes.

Although there have been no empirical estimates of the effect of celebrity endorsements on political outcomes, it is clear that celebrities have the ability to influence the behavior of their fans in other arenas. For example, celebrities are routinely paid to endorse products because it increases perceptions of quality and sales (Kamins 1989; Ohanian 1991). Agrawal and Kamakura (1995) find that the stock value of a firm increases when it announces prominent celebrity endorsements, suggesting that celebrity endorsements are a worthwhile investment. Similarly, Mathur et al. (1997) find that the announced return of Michael Jordan from retirement added over $\$ 1$ billion to the market value of firms whose products were endorsed by Jordan. Although it is unclear that this ability to influence consumers translates to voting decisions, if signals of quality can be effective in settings where the endorser is paid, then they might also be effective in the political realm where the endorser receives no direct payment.

\subsection{The 2008 Democratic Presidential Primary}

The 2008 Democratic presidential primary ("the primary") was distinguished by its length and competitiveness. Hillary Clinton declared for the presidency on January 21, 2007, and was soon followed by Barack Obama on February 11, $2007 .^{2}$ The elections began nearly 1 year later with the Iowa caucuses on January 3, 2008.

Many states attempted to increase their relative importance by holding their elections earlier in the calendar year than they had previously. Except for Iowa and three other approved states, the earliest date allowed by the Democratic National Committee was February 5, 2008, a day on which 22 states held their election. Florida and Michigan held unapproved elections prior to this date.

2. Other candidates for the Democratic nomination included Senators Joe Biden and Chris Dodd, former Senators John Edwards and Mike Gravel, Representative Dennis Kucinich, and Governor Bill Richardson. 
Consequently, Barack Obama and some other candidates removed their names from the ballot in Michigan, and all candidates agreed not to campaign in Florida.

It was not until the last elections, held on June 3, 2008, that Barack Obama received enough delegates to be considered the presumptive nominee. Both leading candidates, Obama and Clinton, won contests throughout the primary season, suggesting neither candidate was able to achieve "political momentum" of the sort described by Knight and Schiff (2010).

Oprah Winfrey's endorsement came well before any voting actually took place. Obama was frequently mentioned as a potential 2008 presidential candidate following his election to the US Senate in 2004. In late 2006, during an interview on Larry King Live, Oprah Winfrey mentioned a preference for Senator Obama. At this point, she stopped short of a clear endorsement and Barack Obama was not a declared candidate. On February 11, 2007, Obama officially declared his candidacy for the Democratic nomination. Oprah Winfrey officially endorsed Obama's candidacy on May 1, 2007.

\subsection{Oprah Winfrey: A Celebrity and an Endorser}

Oprah Winfrey is a celebrity of nearly unparalleled influence. She has been named to Time magazine's list of the 100 most influential people six timesmore than any other individual. She was named one of the 100 most influential people of the 20th century, an honor shared with Albert Einstein, Mohandas Karamchand (Mahatma) Gandhi, and Franklin D. Roosevelt. She was only one of four people who were included on these lists in both the 20th and 21 st centuries. The others were Nelson Mandela, Bill Gates, and Pope John Paul II. According to Forbes magazine, Winfrey was the most powerful celebrity both in 2007 - the year she endorsed Obama - and in 2008.

Winfrey also has an ability to influence the purchasing decisions of her fans through her talk show, magazine, and a list of commercial products she prefers, termed the "Oprah Favorites" list. Her comments and selections can have a large commercial influence. After selecting Ciao Bella sorbet for her 2007 Oprah Favorites list, the company's Web site received 3 million hits in 1 week, compared with an average of 175,000 in previous weeks (Goldman 2007). After challenging her viewers to beat the 1-day sales record for Lance Armstrong "Livestrong" bracelets, 900,000 bracelets were sold-besting previous records by approximately 600,000 .

In addition to her influence on the sales of consumables, Winfrey has also been credited with repopularizing book buying and reading in the United States. Beginning in 1996, Winfrey began operating a book club. She selected books and then approximately 1 month later had an hour-long television show featuring the author of the novel (or an expert on the novel in cases of deceased authors). Butler et al. (2005) find that each of the first 48 books selected for the show became a best seller. This effect persists for the sales of more recent selections, as shown in Table 1. For example, there were approximately 12,000 units of Anna Karenina sold during the 12 weeks prior to its inclusion 
Table 1. Change in Sales Resulting from Oprah's Book Club

\begin{tabular}{|c|c|c|c|c|}
\hline Title & $\begin{array}{c}\text { Date } \\
\text { selected }\end{array}$ & $\begin{array}{c}\text { Unit sales } \\
3 \text { months before } \\
\text { (in thousands) }\end{array}$ & $\begin{array}{c}\text { Unit sales } \\
3 \text { months after } \\
\text { (in thousands) }\end{array}$ & $\begin{array}{l}\text { Ratio of } \\
\text { sales after } \\
\text { to before }\end{array}$ \\
\hline $\begin{array}{l}\text { The Heart is a } \\
\text { Lonely Hunter }\end{array}$ & April 23, 2004 & 6 & 636 & 99 \\
\hline Anna Karenina & May 31, 2004 & 12 & 643 & 54 \\
\hline The Good Earth & September 16, 2004 & 32 & 473 & 14 \\
\hline $\begin{array}{l}\text { A Million Little } \\
\text { Pieces }\end{array}$ & September 22, 2005 & 38 & 3141 & 83 \\
\hline Night & January 16, 2006 & 64 & 1403 & 21 \\
\hline $\begin{array}{l}\text { The Measure } \\
\text { of a Man }\end{array}$ & January 26, 2007 & $<1$ & 866 & 182 \\
\hline The Road & February 28, 2007 & 54 & 988 & 17 \\
\hline
\end{tabular}

Source: Nielsen BookScan. As per the standard of Nielsen BookScan, numbers are rounded to the nearest thousand units. Ratios are calculated using exact sales figures.

in the club. In the 12 weeks following inclusion, this book sold approximately 643,000 units - a staggering increase of $5400 \%$.

Winfrey has created commercial ventures of her own, such as $O$, The Oprah Magazine. Started as a bimonthly magazine in 2001, 1.6 million copies of the initial issue were sold and its popularity led to it becoming a monthly publication 6 months later. According to recent figures from the Audit Bureau of Circulations, sales of Oprah Magazine average 2.4 million issues per month, split roughly equally between subscription and newsstand sales. It is estimated that 16 million people read each issue (Mediamark Research and Intelligence 2007).

The magazine reaches a diverse group of readers. In Table 2, the demographic characteristics of Oprah Magazine readers are compared with those reported for the 2000 US Census. Readers of Oprah Magazine are disproportionately women, college educated, between the ages of 25 and 64 years, married and work in professional occupations. Readers are evenly distributed across the country. The percentage of readers estimated to be white is $70 \%$, slightly smaller than the $75 \%$ in the general population. The African American readership is estimated to be $23 \%, 11$ percentage points higher than their fraction of the general population, whereas $7 \%$ of Hispanics are estimated to be readers, which is 6 percentage points lower than their fraction of the general population.

Winfrey's ability to influence the purchasing decisions of her followers exceeds that of a traditional talk show host. A 2007 poll of likely voters conducted by Forbes Magazine found that Winfrey's influence in the commercial sector may also translate to politics. Fourteen percent of likely voters, and $26 \%$ of likely voters aged between 18 and 24 years, said they would react positively to an endorsement by Winfrey. This was the highest percentage for any celebrity included in the survey (Andelman 2007). A Pew Research Center poll found that $23 \%$ of Democrats said they would be more likely to vote for Winfrey's endorsee. Interestingly, although $69 \%$ of all respondents said that their own vote would be unaffected, $60 \%$ said that they believed the 
Table 2. Demographic Characteristics of Oprah Magazine Readers

\begin{tabular}{|c|c|c|}
\hline Demographic category & Oprah Magazine (\%) & 2000 US Census (\%) \\
\hline Men & 11 & 49 \\
\hline Women & 89 & 51 \\
\hline \multicolumn{3}{|l|}{ Education } \\
\hline College plus & 37 & 24 \\
\hline High school & 58 & 56 \\
\hline Did not graduate high school & 5 & 20 \\
\hline \multicolumn{3}{|l|}{ Age (years) } \\
\hline $18-24$ & 10 & 10 \\
\hline $25-34$ & 18 & 14 \\
\hline $35-44$ & 26 & 16 \\
\hline $45-54$ & 24 & 13 \\
\hline $55-64$ & 14 & 9 \\
\hline $65+$ & 7 & 12 \\
\hline \multicolumn{3}{|l|}{ Employment } \\
\hline Full time & 57 & 55 \\
\hline Part time & 17 & 15 \\
\hline Not working & 27 & 30 \\
\hline Occupation: professional and related & 21 & 12 \\
\hline \multicolumn{3}{|l|}{ Household income $(\$)$} \\
\hline $150,000+$ & 11 & 5 \\
\hline $75,000-149,999$ & 34 & 18 \\
\hline $50,000-74,999$ & 21 & 19 \\
\hline $30,000-49,999$ & 17 & 12 \\
\hline 20,000-29,999 & 7 & 13 \\
\hline \multicolumn{3}{|l|}{ Marital status } \\
\hline Never married & 24 & 27 \\
\hline Now married & 57 & 54 \\
\hline Legally separated/widowed/divorced & 19 & 19 \\
\hline \multicolumn{3}{|l|}{ Race } \\
\hline White only & 70 & 75 \\
\hline Black/African American only & 23 & 12 \\
\hline $\begin{array}{l}\text { Spanish, Hispanic, or Latino origin or } \\
\text { descent }\end{array}$ & 7 & 13 \\
\hline
\end{tabular}

Source: Mediamark Research and Intelligence and the US Census Bureau.

endorsement would help Obama (Pew Research Center 2007). This conflicting survey evidence only serves to highlight the difficulties of empirically demonstrating an effect of celebrity endorsements using survey data.

The scope of Winfrey's influence creates an opportunity to examine the effect of endorsements on political outcomes. Her endorsement generated a large amount of attention in the popular press. In addition, it was the first time that she had ever publicly endorsed a political figure, making her unlikely to be associated with the policies or politics of other political figures.

\section{Empirical Strategy}

Oprah Winfrey's endorsement of Barack Obama prior to the 2008 Democratic presidential primary should have affected the voting preferences of Winfrey's 
fans. Our key identifying assumption is that areas with high per capita circulations of Oprah Magazine and high per capita sales of books in Oprah's Book Club are the areas with more of her fans. It is in these areas that her endorsement should have had the greatest effect.

We assume that voter $i$ 's prior beliefs and other information signals are fully described by a set of demographic and socioeconomic variables, so that the remaining differences in voting behavior are random. Conditional on voting $v$, the probability that voter $i$ votes for Barack Obama is given by the following logit specification:

$\operatorname{Pr}\left(i\right.$ prefers Obama $\left.\mid v_{i}>0\right)=\frac{\exp \left(X_{i} \beta+\operatorname{Oprah}_{i} \lambda\right)}{1+\exp \left(X_{i} \beta+\operatorname{Oprah}_{i} \lambda\right)}$

where $\mathrm{Oprah}_{i}$ is a measure of Oprah's influence and $X_{i}$ a matrix of demographic, socioeconomic, and geographic controls. As we have access to nothing smaller than county-level data, equation (1) is rewritten as a logit model for group-level observations aggregated to location $k$. (Maddala 1983). The dependent variable is the log of the odds ratio of Obama's vote share, VoteShare ${ }_{k}$. It is a linear function of the variable used to measure Oprah's influence, the matrix of covariates, and an error term $u_{k}$, which is assumed to be normally distributed with a zero mean:

$\ln \left(\frac{\text { VoteShare }_{k}}{1-\text { VoteShare }_{k}}\right)=X_{k} \beta+$ Oprah $_{k} \lambda+u_{k}$

This is the form of the equations we use in our estimation. ${ }^{3}$ We control for differences in race, age, sex, marital status, educational attainment, family size, income, poverty status, home ownership, house prices, labor force participation, unemployment, veteran status, and urban/rural mix. Exit polling suggested that gender, race, and income characteristics were particularly important in the 2008 Democratic primary, so quadratic terms for those covariates were added. ${ }^{4}$

In equation (2), an estimated coefficient represents the change in the log odds of a voter voting for Obama that is associated with a unit change in the relevant independent variable. Marginal effects are easier to interpret. The marginal effect of the $m$ th regressor on VoteShare ${ }_{k}$ is calculated as follows:

$\frac{\partial \text { VoteShare }_{k}}{\partial X_{m}}=\beta_{m} \mathrm{E}\left[\right.$ VoteShare $_{k}\left(1-\right.$ VoteShare $\left.\left._{k}\right)\right]$.

This measures the net effect of a regressor on Obama's vote share at the group level. It is possible that Winfrey's endorsement led some voters who disliked Winfrey to vote for a candidate other than Obama, particularly given that Arceneaux and Kolodny (2009) find that interest group endorsements of

3. To test the robustness of the results to the functional form used, we also estimate a specification where VoteShare $_{k}$ is used as the dependent variable. It produces similar results.

4. The results are robust to including these as linear terms. 
Democratic candidates decreased their Republican support. We can identify the net effect of the endorsement but not the exact fractions of voters whose decisions were positively and negatively influenced by it.

The approach described by equations (1) and (2) is also applied to the voter participation decision. Winfrey's endorsement may have affected how many of her fans voted. It may have also affected other people's decision to vote, such as a husband or wife of a fan of Winfrey. They may have been more willing to vote if their partner wanted to, given it is common in couples for both to vote or for neither to vote (Wolfinger and Rosenstone 1980).

The participation equation to be estimated is the same as equation (2), except that the log of the odds ratio of voting participation is the dependent variable. Voting participation is defined as the number of voters divided by the voting-age population. The other variables and the calculation of the marginal effects remain as before.

Our first specification uses the per capita circulation of Oprah Magazine at the county level. To ensure that individuals are not subscribing to Oprah Magazine because of her support for Obama, we use magazine circulation data from 2005 - a year before Winfrey was publicly connected to Obama. Specifically, we estimate the following base models:

$$
\begin{aligned}
& \ln \left(\frac{\text { VoteShare }_{c}}{1-\text { VoteShare }_{c}}\right)=\beta_{0 v}+\eta_{s}+\sum X_{m c} \beta_{v m}+\text { OprahMag }_{c} \lambda_{v}+u_{c} . \\
& \ln \left(\frac{\text { Participation }_{c}}{1-\text { Participation }_{c}}\right)=\beta_{0 p}+\eta_{s}+\sum X_{m c} \beta_{p m}+\text { OprahMag }_{c} \lambda_{p}+u_{c} .
\end{aligned}
$$

In both equations, the first term is a constant, $\eta_{s}$ represents a complete set of dummy variables for states $s, X_{m c}$ is a vector of $m$ demographic and socioeco-

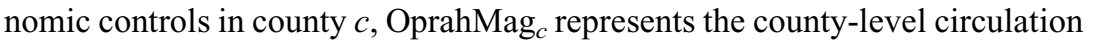
per adult capita of Oprah Magazine in 2005, and the dependent variables are as previously described. State fixed effects are used to control for differences in the timing and voting systems across the states. In addition to the covariates previously described, $X_{m c}$ includes a dummy variable for the seven counties included in the Chicago metropolitan statistical Area. Chicago is a "hometown" for both Obama and Winfrey, so a positive relationship in these counties would generate an upward bias to our estimates of the effect of the endorsement on vote share. To control for general preferences for voting, we include the voting participation rate in the 2004 Democratic presidential primary as an independent variable in equation (5). Throughout the analysis, we allow for an arbitrary variance-covariance matrix accounting for withingroup correlation at the state level. Regressions examining vote share are weighted by the number of voters in each county, whereas regressions examining voter participation are weighted using the voting-age population in each county.

We estimate similar models using the responsiveness of the sales of books included in Oprah's Book Club to create an alternate measure of Winfrey's 
influence. The covariate of interest is a measure of the effect of Winfrey's book club in Nielsen market area $n$, which is the geographic level at which sales are reported. BookSales ${ }_{n}$ is an index that combines the sales of the selected books into a single measure. It is calculated as follows:

BookSales $_{n}=\frac{1}{100} \sum_{b=1}^{B}\left[\left(\frac{1}{T} \sum_{t=1}^{T}\right.\right.$ WeeklySales $_{b n t}-\frac{1}{12} \sum_{t=-11}^{0}$ WeeklySales $\left._{b n t}\right)$

$$
\left./ \text { MarketSize }_{b n}\right] \text {. }
$$

The "Oprah effect" on each book $b$ is the difference between the average weekly sales for $T$ weeks after its selection and the 12 weeks prior to its selection. This is then normalized to 1 to give each title equal importance and then summed across the seven available titles. As was shown in Figure 1, selection in Oprah's Book Club results in an immediate peak and then weekly sales that slowly decrease. To ensure this measure is robust to the time period used, an index using sales for the 4 weeks postselection (i.e., $T=4$ ), an index using sales for the 8 weeks postselection (i.e., $T=8$ ), and an index using sales for the 12 weeks postselection (i.e., $T=12$ ) are used. All other variables are defined as in equations (4) and (5), except that we do not have enough observations to include state fixed effects.

We attempt to address concerns about omitted variables bias through several falsification exercises. First, we estimate models using Oprah Magazine circulation and voting results from the 2004 Democratic Illinois Senate primary, the election that resulted in Obama receiving the Democratic nomination for the 2004 Illinois Senate race. ${ }^{5}$ If the Winfrey's endorsement in 2007 is the cause of the relationship between Oprah Magazine circulation and voting behavior, there should be no relationship between circulation and voting in this 2004 election.

Second, we check if there is a relationship between Oprah Magazine circulation and measures of underlying policy preferences. We estimate the relationship between an index of the voting records of House of Representatives' members and the per capita circulation of Oprah Magazine in congressional districts. We also estimate the relationship between Oprah Magazine per capita circulation and the Democratic vote share in the 2002, 2004, and 2006 US Senate elections. If Oprah Magazine circulation is an exogenous measure of the effect of the endorsement, it should be unrelated to the ideological preferences and electoral outcomes of elected officials.

Third, we use the circulation figures of other magazine titles that have similar readership characteristics to Oprah Magazine. We obtained information

5. Obama convincingly won the Senate general election after his Republican opponent withdrew partway through the race as a result of personal problems. The Democratic primary, however, was contested by seven candidates and polls prior to the voting predicted a close contest (Davey 2004). 
from a market research firm that is used to set advertising prices and help advertisers decide where to place their products. We use this information to select women's magazines with similar readerships to Oprah Magazine and include their per capita circulation figures in the hope that they measure additional preferences or information signals not controlled for by the existing covariates. In addition, we estimate models including the per capita circulation of Ebony, a popular African American magazine.

\subsection{Data}

This analysis requires data on voting results, magazine circulation, book sales, voting report cards for elected officials (for policy preferences), and countylevel demographic and socioeconomic data. Given the range of sources involved, more details are provided in a data appendix that is available from the authors.

Election data are from the Atlas of U.S. Elections. ${ }^{6}$ These data are taken from official returns. The 2008 Iowa caucuses report delegates rather than votes, so an unofficial count reported by the Associated Press matching official delegate numbers is used for that election. In total, 45 states and the District of Columbia are included in this analysis. ${ }^{7}$ County-level turnout figures for the 2004 Democratic primary were needed to analyze voter participation. This was not available for Colorado, Maine, Nevada, and Utah, limiting that analysis to 41 states and the District of Columbia.

Data on magazine circulation is from the Audit Bureau of Circulations, an industry body that is the primary source of circulation data used for setting rates for advertisement sales. We use their Supplemental Data Reports, which provide county-level sales information. ${ }^{8}$ Book sales data come from Nielsen BookScan (Nielsen). Nielsen provides a sales-tracking service that covers, according to their estimates, $75 \%$ of the United States' retail book market. Transaction data for the sales of individual titles are collected by book retailers and reported on a weekly basis. Nielsen began reporting data at a subnational level in January 2004, and has maintained a consistent panel of retailers and weighting methodology since then.

Nine titles were included in Oprah's Book Club between the start of 2004 and Winfrey's endorsement in May 2007. Two selections cannot be used in this analysis. There are insufficient preselection sales data for One Hundred Years of Solitude, which was selected by Winfrey in January 2004, and there are no preselection sales data for a compilation of three novels by William Faulkner,

6. Available online at http://www.uselectionatlas.org

7. It is not possible to include five states in the analysis: Michigan, because Obama was not on the ballot; Kansas, North Dakota, and Alaska, because they do not report county-level voting information; and Texas, because a primary and a caucus were held on the same day, possibly creating different incentives in voting behavior.

8. Audit Bureau of Circulations data are used in Duggan's (2001) examination of the relationship between gun ownership and crime. 
which was produced specifically for the Oprah Book Club. The seven titles we use are listed in Table 1.

Book data are available for Nielsen market areas, which are 99 geographic areas defined by Nielsen BookScan and based on major cities. To account for the varying sizes of Nielsen market areas and the seasonality in the book market, the increase in book sales is scaled by MarketSize ${ }_{z n}$, which represents the average weekly aggregate book sales in each Nielsen market area for the 12-month period spanning the 6 months before the selection and the 6 months after the selection. ${ }^{9}$

Data on elected officials' voting records are from the National Journal - a magazine focused on domestic political issues and activities. Since 1981, the National Journal has gathered data on the voting behavior of members of the Senate and House of Representatives and created an annual ranking of their ideological preferences. We use data from the magazine's "liberal" rankings. National Journal editors selected 216 key votes from the 2007 legislative calendar (107 Senate votes and 109 House votes) to calculate percentile rankings of how liberal each representative was with respect to economic, social, and foreign policy.

Demographic and socioeconomic data are from the 2000 Census, using county-level extracts from the National Historical Geographic Information System. One county in Hawaii (Kalawao) is not used because not all of the measures can be calculated. This left 2610 counties across 45 states in the sample for the magazine analysis and 87 Nielsen market areas for the book sales analysis.

\section{Vote Share and Participation Results}

Throughout this analysis, the key underlying assumption is that geographic variation in commercial indicators of Winfrey's success is a proxy measure for the number of her fans in an area. We posit that, in areas with a greater number of fans, the endorsee should enjoy a greater degree of political success and there should be higher levels of voter participation.

\subsection{The Effect of the Endorsement Using Magazine Circulation}

We first use the per capita circulation of Oprah Magazine as a proxy measure of the number of fans in each county and estimate equation (4). Table 3 contains the estimated marginal effects for this model. Column 1 contains estimates for the entire sample. The estimated marginal effect of the Oprah Magazine measure is positive, large, and statistically significant at the 0.01 level. In addition to magazine circulation, positive and statistically significant coefficients are estimated for female labor force participation and the percent

9. To create corresponding demographic and socioeconomic variables, we match counties to Nielsen market areas using the following procedure. First, we identify the counties in the metropolitan statistical areas where the cities named in the Nielsen market areas are located. If the counties in a Nielsen market area span more than one state, only the counties in the state that made up the majority of the voting-age population are used. There are two Nielsen market areas where no single state held the majority of the voting-age population; these are excluded from the analysis. 
Table 3. Obama's Votes and the Circulation of Oprah Magazine

\begin{tabular}{|c|c|c|c|}
\hline & (1) All states & (2) Primary & (3) Caucus only \\
\hline Oprah Magazine & $3.00(0.86)^{\star \star \star}$ & $3.11(0.90)^{\star \star \star}$ & $4.81(1.03)^{\star \star \star}$ \\
\hline Male & $-3.18(2.46)$ & $-3.26(2.52)$ & $0.61(3.00)$ \\
\hline Male $^{2}$ & $2.79(2.42)$ & $2.83(2.47)$ & $-0.47(2.72)$ \\
\hline White & $0.78(0.19)^{\star \star \star}$ & $0.78(0.19)^{\star \star \star}$ & $1.14(0.40)^{\star \star \star}$ \\
\hline White $^{2}$ & $-0.58(0.16)^{\star \star \star}$ & $-0.59(0.17)^{\star \star \star}$ & $-0.45(0.31)$ \\
\hline Black & $0.74(0.14)^{\star \star \star}$ & $0.73(0.15)^{\star \star *}$ & $-0.001(1.47)$ \\
\hline Black $^{2}$ & $0.07(0.14)$ & $0.07(0.14)$ & $11.16(12.55)$ \\
\hline Hispanic & $-0.44(0.20)^{\star \star}$ & $-0.45(0.20)^{\star \star}$ & $0.33(0.77)$ \\
\hline Hispanic $^{2}$ & $1.05(0.37)^{\star \star \star}$ & $1.06(0.37)^{\star \star *}$ & $-0.23(1.17)$ \\
\hline HighSchGrad & $0.43(0.18)^{\star \star}$ & $0.43(0.19)^{\star \star}$ & $-0.08(0.18)$ \\
\hline CollegeGrad & $0.64(0.20)^{\star \star \star}$ & $0.64(0.21)^{\star \star \star}$ & $0.39(0.18)^{\star \star}$ \\
\hline Married & $-0.39(0.12)^{\star \star \star}$ & $-0.37(0.12)^{\star \star \star}$ & $-0.66(0.48)$ \\
\hline Divorce+Sep & $-0.22(0.25)$ & $-0.19(0.26)$ & $-1.25(0.91)$ \\
\hline Widowed & $-2.79(0.64)^{\star \star \star}$ & $-2.81(0.64)^{\star \star \star}$ & $-0.67(0.65)$ \\
\hline Pop40to64 & $0.35(0.15)^{\star \star}$ & $0.33(0.16)^{\star \star}$ & $0.72(0.57)$ \\
\hline Pop65plus & $1.07(0.20)^{\star \star \star}$ & $1.07(0.20)^{\star \star \star}$ & $0.01(0.48)$ \\
\hline FamilySize & $0.12(0.04)^{\star *}$ & $0.12(0.04)^{\star \star *}$ & $0.10(0.06)^{\star}$ \\
\hline Urban & $-0.04(0.02)$ & $-0.04(0.02)^{\star}$ & $-0.02(0.01)^{\star}$ \\
\hline Veteran & $-0.003(0.19)$ & $-0.01(0.19)$ & $0.71(0.18)^{\star \star \star}$ \\
\hline Unemp_Male & $-0.08(0.19)$ & $-0.09(0.19)$ & $-0.09(0.41)$ \\
\hline Unemp_Female & $0.13(0.14)$ & $0.12(0.14)$ & $0.58(0.59)$ \\
\hline LbrFP_Male & $-0.10(0.09)$ & $-0.11(0.09)$ & $0.02(0.19)$ \\
\hline LbrFP_Female & $0.67(0.14)^{\star \star \star}$ & $0.68(0.14)^{\star \star \star}$ & $-0.02(0.14)$ \\
\hline Poor & $-0.24(0.25)$ & $-0.22(0.26)$ & $0.13(0.73)$ \\
\hline MedianIncome (\$m) & $-2.15(2.38)$ & $-2.24(2.43)$ & $13.98(4.84)^{\star \star \star}$ \\
\hline Medianlncome ${ }^{2}\left(\$ m^{2}\right)$ & $-8.87(19.02)$ & $-8.12(19.35)$ & $-146.17(42.42)^{\star \star \star}$ \\
\hline OwnHome & $0.0001(0.09)$ & $0.003(0.09)$ & $0.07(0.16)$ \\
\hline Chicago & $-0.02(0.01)^{\star \star}$ & $-0.02(0.01)^{\star}$ & $0.05(0.01)^{\star \star \star}$ \\
\hline LowQuartileHouse (\$m) & $0.58(0.24)^{\star *}$ & $0.59(0.24)^{\star *}$ & $0.55(0.56)$ \\
\hline MedianHouse (\$m) & $-0.08(0.15)$ & $-0.07(0.16)$ & $-0.05(0.63)$ \\
\hline UpperQuartileHouse (\$m) & $-0.09(0.19)$ & $-0.10(0.19)$ & $-0.04(0.53)$ \\
\hline$R^{2}$ & 0.9152 & 0.9148 & 0.9307 \\
\hline$N$ & 2610 & 2132 & 478 \\
\hline
\end{tabular}

State fixed effects are included in all regressions. Coefficients and standard errors are transformed using E[VoteShare $x$ $(1-$ VoteShare)] so coefficients can be interpreted as marginal effects. Standard errors are in parentheses and are clustered at the state level. Regressions and the transformation are weighted using number of voters.

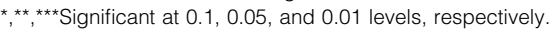

of the population that are white, black, high school graduates, older than 40 years, and college graduates, whereas coefficients for percent married, widowed, urban, and Hispanic are negative and statistically significant. ${ }^{10}$

Caucuses and primary elections result in very different turnouts: In our sample, caucuses had an average turnout of $0.4 \%$ of the voting-age population, whereas primary elections had an average turnout of $18 \%$. As Winfrey's

10. The direction and statistical significance of the variables with square terms included in the regression, including percentage white, black, and Hispanic, are calculated as the nonlinear combination of the coefficients on the linear and square terms evaluated at sample means. Standard errors are calculated using the delta method. 
endorsement could plausibly have different effects under the two systems, results are reported for separate samples of primary-only counties and caucus-only counties. Column 2 contains the results for states that use primary voting. These results are qualitatively similar in magnitude and sign to those in column 1. Column 3 contains estimates for caucus states. In these states, the marginal effect of changes in Oprah Magazine circulation per capita is over 1.5 times the size of the estimated effect for primary states, suggesting that Winfrey's endorsement may have had a greater impact on Obama's vote share in states with a caucus system.

Table 4 provides some insight into the relative magnitude of the estimated marginal effects. The entries in the table represent the estimated change in Obama's vote share due to a $10 \%$ change in the value of various independent variables. For example, a 10\% change in the per capita circulation of Oprah Magazine is associated with a 0.34 percentage point change in the vote share for Obama in a primary state. This is larger in magnitude than the effect for the percent of the population that is urban or poor, but less than the estimated effect of marital status, age, and labor force participation.

As already discussed, a celebrity endorsement may increase overall voter participation. This effect may be different to the change in vote share because some individuals may be induced to vote as a result of group behavior but may not actually choose the endorsee once they are at the polling location. Table 5 contains the estimated marginal effects on participation-defined as the

Table 4. Percentage Point Changes in Vote Share for a 10\% Change in Independent Variables

\begin{tabular}{|c|c|c|}
\hline & Primary states & Caucus states \\
\hline$\%$ Male & -15.65 & 2.98 \\
\hline$\%$ White & 5.58 & 9.62 \\
\hline$\%$ LFP female & 3.92 & -0.13 \\
\hline High school graduate & 2.37 & -0.47 \\
\hline$\%$ Married & -2.08 & -3.86 \\
\hline$\%$ Widowed & -2.02 & -0.42 \\
\hline$\% 65+$ & 1.81 & 0.02 \\
\hline College graduates, $\%$ & 1.62 & 1.11 \\
\hline$\%$ 40-64 years & 1.33 & 2.91 \\
\hline$\%$ Black & 0.94 & 0.00 \\
\hline$\%$ LFP male & -0.78 & 0.15 \\
\hline \% Hispanic & -0.43 & 0.17 \\
\hline Circulation of Oprah Magazine, \% & 0.34 & 0.63 \\
\hline$\%$ Urban & -0.32 & -0.15 \\
\hline$\%$ Divorced or separated & -0.24 & -1.45 \\
\hline$\%$ Poor & -0.20 & 0.08 \\
\hline$\%$ Unemployed female & 0.07 & 0.24 \\
\hline \% Unemployed male & -0.05 & -0.04 \\
\hline$\%$ Veteran & -0.01 & 0.93 \\
\hline
\end{tabular}

LFP, labor force participation. The marginal effects for the sex and race variables are calculated as the nonlinear combination of the coefficients on the linear and square terms, evaluated at sample means. In these cases, standard errors are calculated using the delta method. 
Table 5. Voter Participation and Circulation of Oprah Magazine

\begin{tabular}{llll}
\hline & (1) All states & (2) Primary & (3) Caucus only \\
\hline Oprah Magazine & $1.09(0.52)^{\star \star}$ & $1.29(0.53)^{\star \star}$ & $0.10(0.50)$ \\
$R^{2}$ & 0.9442 & 0.8581 & 0.9602 \\
$N$ & 2404 & 2103 & 301 \\
\hline
\end{tabular}

Unreported covariates are as in Table 3. All specifications include a complete set of state dummy variables. Coefficients and standard errors are transformed using E[Participation $\times(1-$ Participation $)]$. Standard errors are in parentheses and are clustered at the state level. Regressions and the transformation are weighted using adult population.

$*, * *, * *$ Significant at $0.1,0.05$, and 0.01 levels, respectively.

percentage of the adult population voting in the election. Results are reported for three samples: all states, primary states, and caucus states. ${ }^{11}$

There is a positive and statistically significant effect on participation for Oprah Magazine circulation in the samples of all states and primary-only states. There is no statistically significant effect in caucus states. This lack of an effect suggests that perhaps the endorsement is insufficient to overcome the high costs of caucus voting. The unreported marginal effects show that, in general, participation is positively associated with higher labor force participation, median income, voter participation in 2004, and the percent of the population that is white, black, or a military veteran.

\subsection{The Effect of the Endorsement Using Book Sales}

An analysis similar to that contained in Table 3 is conducted using the sales of books included in Oprah's Book Club. Columns 1-4 of Table 6 contain the estimated marginal effects of this measure of Winfrey's popularity on Obama's vote share. Results are reported for a sample of all states and primary-only

Table 6. Obama's Votes, Voter Participation, and Oprah's Book Club

\begin{tabular}{|c|c|c|c|c|c|c|c|c|}
\hline & \multicolumn{4}{|c|}{ Vote share } & \multicolumn{4}{|c|}{ Participation } \\
\hline & \multicolumn{2}{|c|}{4 weeks } & \multicolumn{2}{|c|}{12 weeks } & \multicolumn{2}{|c|}{4 weeks } & \multicolumn{2}{|c|}{12 weeks } \\
\hline & $\begin{array}{l}\text { (1) All } \\
\text { DMAs }\end{array}$ & $\begin{array}{l}\text { (2) Primary } \\
\text { only }\end{array}$ & $\begin{array}{l}\text { (3) All } \\
\text { DMAs }\end{array}$ & $\begin{array}{l}\text { (4) Primary } \\
\text { only }\end{array}$ & $\begin{array}{l}\text { (5) All } \\
\text { DMAs }\end{array}$ & $\begin{array}{l}\text { (6) Primary } \\
\text { only }\end{array}$ & $\begin{array}{l}\text { (7) All } \\
\text { DMAs }\end{array}$ & $\begin{array}{l}\text { (8) Primary } \\
\text { only }\end{array}$ \\
\hline Book & 1.51 & 1.82 & 1.58 & 1.93 & 1.86 & 2.18 & 1.91 & 2.17 \\
\hline Sales & $(0.74)^{\star \star}$ & $(0.82)^{\star \star}$ & $(0.80)^{\star}$ & $(0.91)^{\star \star}$ & $(0.70)^{\star \star}$ & $(0.60)^{\star \star \star}$ & $(0.74)^{\star \star}$ & $(0.72)^{\star \star \star}$ \\
\hline$R^{2}$ & 0.8872 & 0.9016 & 0.8885 & 0.9032 & 0.9048 & 0.8231 & 0.9038 & 0.8166 \\
\hline$N$ & 87 & 76 & 87 & 76 & 81 & 75 & 81 & 75 \\
\hline
\end{tabular}

Unreported covariates are as in Table 3; no state fixed effects are included. Coefficients and standard errors in the vote share regressions are transformed using E[VoteShare $\times(1-$ VoteShare $)]$, whereas coefficients and standard errors in the voter participation regressions are transformed using $E[$ Participation $\times(1-$ Participation $)]$. Vote share regressions and transformations are weighted using the number of voters, whereas voter participation regressions and transformation are weighted using adult population. DMAs are Nielsen Designated Market Areas.

${ }^{\star}, * \star,{ }^{* \star *}$ Significant at $0.1,0.05$, and 0.01 levels, respectively.

11. For this and all remaining tables, only the coefficients of interest are reported. Results for all covariates are contained in a results appendix, which is available from the authors. 
states. Given that only 11 Nielsen market areas are in states that held caucuses, we are unable to separately estimate the model for this group.

Each pair of columns in Table 6 contains results for an index that measures the variation in book sales across Nielsen market areas at 4 and 12 weeks after a title had been selected. ${ }^{12}$ There is a positive and statistically significant effect of book sales on Obama's vote share that is robust to the postselection period of sales used. The estimated effects for the percentage of the population that is divorced and that owns their home are also statistically significant at conventional levels. Few other covariates are statistically significant at conventional levels, a consequence of the small sample size.

Columns 5-8 of Table 6 contain results for the estimated voter participation effects when using book club sales. There is a statistically significant effect for book sales on voter participation in the sample of all Nielsen market areas for both sales time periods. There is also a positive and statistically significant effect for both measures of book sales in primary-only areas. Compared with the vote share equations, a larger number of covariates are statistically significant. It is of interest that the percentage of the population older than 40 years is negatively related to participation. The omitted category is individuals aged 18-39 years, suggesting that the turnout was greater among younger individuals during the 2008 primary.

These results using books sales provide support for the results using magazine subscriptions. The estimated effect of Winfrey's endorsement is consistent across the two commercial indicators of her influence.

\subsection{Falsification Exercises}

Although consistent results across both commercial indicators somewhat address concerns that unobserved preferences are biasing our estimates of the effect of Winfrey's endorsement, we conduct several falsification tests to further test for the presence of omitted variables.

3.3.1 Illinois Senate Primary in 2004. There should be no connection between Oprah Magazine circulation and Obama's previous electoral outcomes. Prior to his 2008 campaign, Obama was involved in only three other types of elections-successful Illinois State Senate elections in 1996, 1998, 2000, and 2002; a failed run for the US House of Representatives in 2000; and his 2004 election to the US Senate. This last election is the only feasible event for a falsification exercise, given it was a statewide contest and therefore involved voters in all of Illinois's 102 counties. The 2004 Senate election also contained a Democratic primary, which is more similar to the election analyzed here than his general Senate election. We examine results from this primary.

12. The empirical specification is also estimated using 8 weeks of postselection sales data, with similar results. It is contained in the results appendix. 
Table 7. Obama's Votes and Voter Participation in 2008 and in the 2004 Illinois Senate Primary

\begin{tabular}{llccc}
\hline & $\begin{array}{c}\text { (1) } 2008 \\
\text { Illinois vote } \\
\text { share }\end{array}$ & $\begin{array}{c}\text { (2) } 2004 \\
\text { Illinois vote } \\
\text { share }\end{array}$ & $\begin{array}{c}\text { (3) } 2008 \\
\text { Illinois participation }\end{array}$ & $\begin{array}{c}\text { (4) 2004 Illinois } \\
\text { participation }\end{array}$ \\
\hline $\begin{array}{l}\text { Oprah } \\
\text { Magazine }\end{array}$ & $0.99(2.89)$ & $-10.86(14.93)$ & $6.95^{*}(3.91)$ & $2.86(2.64)$ \\
$R^{2}$ & 0.9562 & 0.9470 & 0.8897 & 0.9158 \\
$N$ & 102 & 102 & 102 & 102 \\
\hline
\end{tabular}

Unreported covariates are as in Table 3. The weighting structure and transformations are the same as in Table 6. Standard errors are in parentheses.

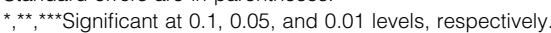

Table 7 contains the results with both vote share and participation as dependent variables in both the 2004 Senate primary and 2008 presidential primary in Illinois. Columns 1 and 2 contain the results for vote share. Although there is no statistically significant effect for Oprah Magazine circulation in either specification, in the estimates using 2008 vote shares in Illinois, the Oprah Magazine variable is positive and roughly similar in magnitude to the main results, whereas those for 2004 are large and negative.

Columns 3 and 4 contain the 2004 and 2008 Illinois results with voter participation as the dependent variable. ${ }^{13}$ The 2008 coefficient on Oprah Magazine circulation is positive and statistically significant at the 0.1 level, whereas the equivalent coefficient is not significant in the 2004 results. Taken together, these vote share and participation results provide suggestive evidence that there is no preexisting correlation between support for Winfrey and Obama.

3.3.2 Policy Preferences. A relationship between the circulation of Oprah Magazine and the underlying policy preferences at the local level could also affect the results. For example, if voters in areas with high levels of Oprah Magazine circulation tend to support more liberal candidates and Obama is supported by liberals, the main results in Table 3 could be driven by underlying preferences and not the endorsement. To check this, we estimate the relationship between the voting records of congressional representatives and Oprah Magazine circulation. Specifically, we estimate a specification of equation (4) with the voting index numbers of congressional representatives as the dependent variable, and Oprah Magazine circulation and the covariates defined at the congressional district level. The voting index is a National Journal ranking of liberal voting for the representative serving constituents in district $d$ during the 2007 legislative calendar, and is between 0 and 100. All other variables are as defined in equation (4). Given that Obama was the most liberal US Senator in 2007 according to the National Journal, it would be a particular concern if

13. In this falsification test, turnout data from the 2002 Democratic Senate primary are used as a measure of the underlying preference for voting. 
the estimated effect of Oprah Magazine circulation is positive as it would indicate that voters in areas where circulation of Oprah Magazine is higher are more likely to support candidates who are ideologically similar to Obama. County-level magazine, demographic, and socioeconomic data were mapped to the boundaries of the 108th Congress. Counties crossing congressional district lines are not included. ${ }^{14}$

Column 1 of Table 8 contains the estimated coefficients from specifications of equation (4) using the overall composite vote ranking. The estimated effect of circulation of Oprah Magazine is small in magnitude and very imprecisely estimated. ${ }^{15}$ Columns 2-4 contain the estimated coefficients from for all three subcategories (economic policy, social policy, and foreign policy). Similar to column 1 , there is no statistically significant relationship between circulation of Oprah Magazine and the voting records of the elected officials. ${ }^{16}$ This lack of an effect suggests that areas with differentially higher circulation of Oprah Magazine are not likely to elect politicians with any particularly liberal (or conservative) set of policy preferences. Column 5 contains the estimates for equation (4) with the log odds of voting for Obama as the dependent variable using this smaller sample of counties. Although the result is not statistically significant on this smaller sample, it is still positive and is larger than the main estimates in Table 3 .

To examine whether sample size is driving the lack of an effect in columns (1) - (4) we conduct a further falsification test using county-level voting outcomes in United States Senate elections in 2002, 2004, and 2006 to assess the possible relationship between ideological preferences and the Oprah Magazine circulation. Using three cycles of elections ensures that each Senate seat is included, and each county is counted at least twice. Furthermore, this generates a much larger sample size (5,020 county observations) than for the analysis in

Table 8. Policy Preferences and Oprah Magazine Circulation

\begin{tabular}{lcccccc}
\hline & $\begin{array}{c}\text { (1) National } \\
\text { Journal } \\
\text { composite }\end{array}$ & $\begin{array}{c}\text { (2) National } \\
\text { Journal } \\
\text { economic }\end{array}$ & $\begin{array}{c}\text { (3) National } \\
\text { Journal } \\
\text { social }\end{array}$ & $\begin{array}{c}\text { (4) National } \\
\text { Journal } \\
\text { foreign }\end{array}$ & $\begin{array}{c}\text { (5) Obama } \\
\text { vote share }\end{array}$ & $\begin{array}{c}\text { Democratic } \\
\text { vote share }\end{array}$ \\
\hline Oprah & 85.06 & 556.13 & 252.75 & -1206.79 & 4.57 & -6.03 \\
Magazine & $(611.30)$ & $(610.64)$ & $(935.49)$ & $(792.22)$ & $(5.13)$ & $(4.70)$ \\
$R^{2}$ & 0.8895 & 0.8574 & 0.8358 & 0.8298 & 0.8698 & 0.7648 \\
$N$ & 224 & 224 & 224 & 224 & 224 & 5020 \\
\hline
\end{tabular}

Unreported covariates are as described in Table 3. Vote ranking specifications are weighted using adult population, whereas vote share specifications are weighted using the number of voters. Standard errors are in parentheses and are clustered at the state level.

14. Approximately $15 \%$ of counties crossed congressional district lines.

15. A 1 standard deviation change in the circulation of Oprah Magazine would result in a 0.34 unit change in composite National Journal ranking, which ranges from 0 to 100.

16. Although each index has the same range, their mean and standard deviation varies because the number of votes and similarity of the voting patterns is different in each subject area. Therefore, the coefficients should not be compared directly across the four columns, although in each case the coefficients are small in magnitude and imprecisely estimated. 
column (1) - (4). Using these observations, we estimate a specification of equation (4) with the $\log$ of the odds-ratio of the Democratic vote share as the dependent variable. Column (6) of Table 8 contains the estimated marginal effect of Oprah Magazine circulation on Democratic vote share in these Senate elections. There is no statistically significant relationship between Oprah Magazine circulation and Democratic vote share.

3.3.3 Other Magazines. There is some concern that buyers of women's magazines like Oprah Magazine differ from nonbuyers in ways not controlled for in these regressions. To address this concern, we include the per capita circulations of magazines with similar readership demographics to Oprah Magazine in equations (4) and (5). In order to identify the appropriate magazines, we obtained demographic data from Mediamark Research and Intelligence on Oprah magazine and 15 magazines identified by Mediamark as having potentially similar readership demographics. Mediamark is a company that provides readership information to magazines and advertisers that is used to set advertising rates. We identify Self and People as the two magazines with the most similar readers, using demographic factors such as sex, age, race, income, occupation, and marital status. ${ }^{17,18}$

Given the fact that all the information received by the voters may affect their voting behavior, it is important to consider whether these magazines may include stories that are more favorable to one candidate over another. Like Oprah Magazine, Self and People have primarily female readerships. They appear to provide more information about Hillary Clinton than Barack Obama, both in overall terms and in terms of coverage that could be considered positive. If anything, this type of coverage could limit finding an effect of Winfrey's endorsement using magazine subscription information.

Although these two magazines most closely match Oprah Magazine readers across a wide variety of characteristics, the fact that Obama is the first African American nominee of a major party means race may be a primary characteristic of interest. Therefore, we also estimate our equations with the per capita circulation of Ebony magazine. According to Amazon.com, "Ebony is a black-oriented, general, picture magazine dealing primarily with contemporary topics.” If the results of Oprah Magazine are due to the magazine's disproportionate African American readership, this effect should also exist for areas where Ebony is popular. ${ }^{19}$

17. Although the most similar demographic base to Oprah Magazine is Martha Stewart Living, this magazine was not included because 2005 was the year immediately following the arrest and imprisonment of Martha Stewart for obstruction of justice and lying to investigators. The magazine suffered a sharp decline in circulation that year, and it is likely that this decline occurred in a nonrandom manner.

18. For each demographic characteristic (race, sex, income, etc.), the average difference between the readership of Oprah Magazine and 15 other magazines was calculated. The two magazines with the smallest average difference across categories were selected.

19. According to Mediamark, the readership of Ebony is nearly $88 \%$ African American. 
Table 9 contains the estimated marginal effects from a specification of equation (4) with the county-level circulation of other magazines included as covariates. Column 1 contains results with vote share as the dependent variable for a sample of primary voting states. The estimated marginal effect for circulation of Winfrey's magazine is larger than the estimate in Table 3. In addition, the estimated effect for Self magazine is negative and statistically significant. There is no statistically significant effect for People magazine.

Column 2 contains results for primary states with participation as the dependent variable. Columns 3 and 4 contain the equivalent results for caucus states. There is a positive and statistically significant effect of Oprah Magazine circulation on vote share but no effect on participation. The estimated marginal effect on participation for Oprah Magazine is slightly larger than in Table 5, but not to the same degree as in the vote share specification. The estimated effects of Self and People on voter participation are statistically insignificant at conventional levels. Columns 5-8 contain similar results with per capita circulation of Ebony magazine included as a covariate. The only statistically significant estimate for Ebony is a negative coefficient for vote share in caucus states. This effect is significant at the 0.10 level.

In these specifications, we are not necessarily expecting to find no relationship between women's magazines and Obama's voting outcomes; rather, we are concerned that such relationships are positive. It is not surprising that there is a negative relationship between Self and Obama's vote share: Self magazine named Hillary Clinton 1 of the 10 most inspirational women in America for the fourth year in a row in September 2007. Indeed, prior to the endorsement, Clinton had been mentioned more frequently in Oprah Magazine than Obama had. $^{20}$ The results using these three magazines suggest that the underlying preferences of Oprah Magazine readers are not driving the earlier estimates of the endorsement's effect. If anything, it appears that any unobserved underlying preferences are generating a downward bias in the main estimates of the endorsement's effect.

\section{Winfrey's Endorsement and Campaign Contributions}

An endorsement may also increase campaign contributions. This is another way through which an endorsement may increase an endorsee's votes, as increased campaign spending is associated with better political outcomes (Levitt 1994). Moreover, campaign contributions were collected both before and after Winfrey's endorsement, meaning county-level fixed effects can be used to control for time-invariant characteristics, including underlying political preferences.

20. More generally, Oprah Winfrey fans may have been more positively predisposed to Clinton than to Obama. In a news article at the time of the endorsement, political scientist Andrea Gillespie was quoted as saying, "Oprah's audience isn't necessarily an Obama crowd, they tend to be older, less educated women who are home to watch her show at 4 p.m ... those fans are more likely to support his rival Democrat, Sen. Hillary Clinton” (Scott 2007). 


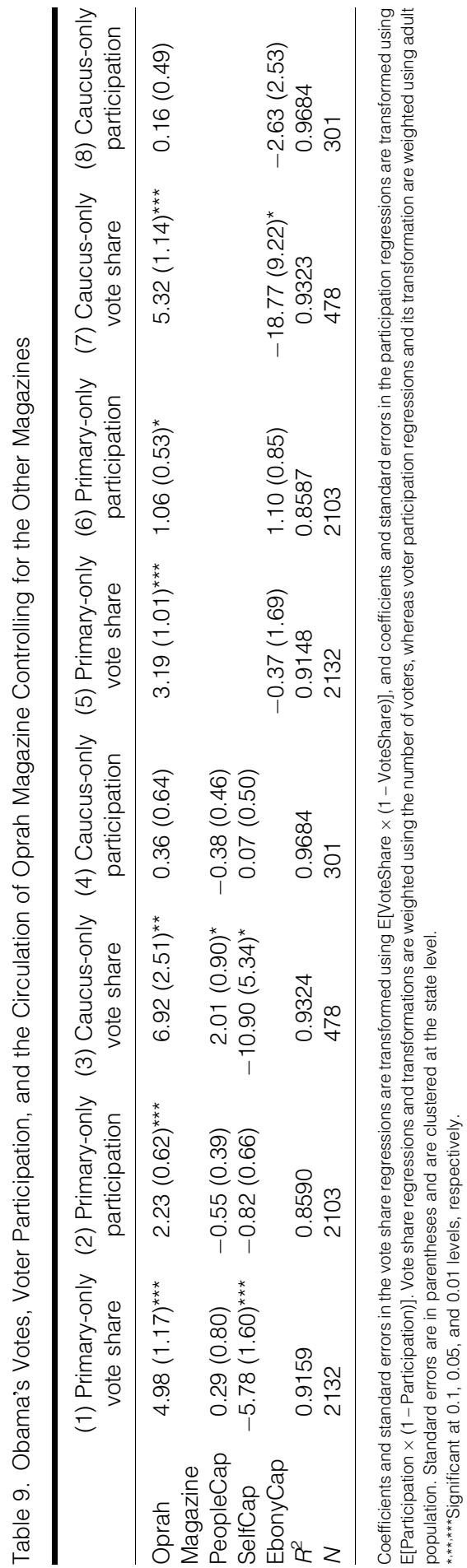


It is logical that the mechanisms driving voting behavior may also affect contribution decisions. Fans who believe a candidate is of higher quality following a celebrity endorsement will be more likely to contribute financially to the candidate's campaign. Contributing to a campaign, however, probably requires a more intense preference for the candidate than voting: A much smaller percentage of Americans donate to presidential campaigns than vote in primaries or general elections. Empirically identifiable effects may therefore only be observed in areas with high concentrations of fans.

The relative rarity of donating means many counties report no contributions each week. Therefore, we focus on the decision to donate rather than on the amount contributed. We use the total number of contributions made each week as the dependent variable and only consider data in the 300 largest counties. ${ }^{21,22}$

We estimate a fixed-effects negative binomial regression model. In the presence of panel data and overdispersion, Allison and Waterman (2002) suggest that a negative binomial model with dummy variables for fixed effects is the most appropriate model. The analysis is limited to contributions one quarter before and one quarter after the endorsement, and we allow for an arbitrary variancecovariance matrix accounting for within-group correlation at the county level.

A number of factors other than the endorsement may have occurred during the post-endorsement time period. To control for these factors, we implement a difference-in-differences identification strategy. We assume that counties with a greater number of fans receive more of a "treatment" from the endorsement than those with fewer fans. We construct three distinct sets of treatment and control groups with samples split at the median, 75th, and 95th percentiles of Oprah Magazine circulation. ${ }^{23}$ Given that the pretreatment contribution trends are the same across groups, as is shown below, this identification strategy should accurately estimate the endorsement's impact on contributions.

It is not clear what effect the endorsement should have on contributions to Obama's opponents in the Democratic primary. It is possible that group behavior and negative responses to the endorsement could increase the contributions of other candidates. Therefore, we conduct falsification exercises using the contributions data of candidates in the Republican primary. We use contributions to the two leading Republican primary candidates, Governor Mitt Romney and Senator John McCain, who are likely to be less affected by Winfrey's endorsement than Obama's competitors in the Democratic primary.

21. These counties make up the majority of the sample population and the vast majority of the contribution activity during the time period under consideration. In a sample containing all counties, $89.9 \%$ of the county-week observations are zero. In contrast, among the 300 largest counties, only $46 \%$ of the county-week observations are zero. This sample of the largest counties represents $90 \%$ of all contributions and $93 \%$ of all dollars contributed.

22. One county was eliminated because no contributions were ever recorded there, resulting in 299 counties.

23. The decision to contribute is costly and therefore should require more intense support than the decision to vote. As a result, there may only be a detectable effect in counties with high concentrations of fans. This is particularly true because we are only able to observe donations that are above $\$ 200$. 
Campaign contributions data are obtained from detailed files of the Federal Elections Commission, which includes the contribution amounts and exact address information for all individuals who contribute $\$ 200$ or more to a candidate (up to the maximum allowed level of \$2300). Using contributors' zip code of residence, contributions were aggregated into weekly totals for each county included in this analysis. ${ }^{24}$ Only contributions from private individuals are counted, and negative contributions are dropped from those data. ${ }^{25}$

An important caveat to this analysis is that we do not have data on donors giving under \$200. The Campaign Finance Institute estimates that Obama received $32 \%$ of his contributions from these donors during 2007. Given the expected effects of the endorsement, this probably creates a downward bias in the estimated effect of the endorsement on fans' contributions.

\subsection{The Endorsement's Effect on Campaign Contributions}

The simplest estimate of the effect of the endorsement on contributions is to compare the mean weekly contributions for counties in the treatment and control groups before and after the endorsement. In unreported results, there is a positive difference in these means for counties split at the 75 th and 95 th percentiles. ${ }^{26}$ For the sample split at the 95 th percentile, this result is driven primarily by increases in counties where the circulation of Oprah Magazine is relatively high, rather than decreases in lower circulation counties, as shown in Figure 2. The dotted vertical line represents the week of Winfrey's endorsement. The pre-endorsement trends of contributions are similar, with counties above the 95th percentile in Oprah Magazine circulation having greater average contributions in only 7 of the 12 weeks before the endorsement. There is an increase in contributions in high-circulation counties following the endorsement, with these counties having higher average contributions in all 12 weeks.

A difference-in-differences estimate is more precisely estimated using a negative binomial regression with county fixed effects. We include a cubic weekly time trend and a dummy variable to account for the peak in contributions at the end of each FEC filing period. Estimates are weighted using the adult population in each county. Table 10 contains the results from this specification. Columns 1-3 show the results when the treatment group is all counties with Oprah Magazine circulations above the 75 th percentile. ${ }^{27}$ There is a positive and statistically significant result $(p$ value $<0.05$ ) for contributions to Obama, suggesting that

24. Approximately $14 \%$ of observations in this data set are in a zip code that overlapped a county border. In these cases, contributions were allocated to the primary county attached to that zip code.

25. Negative contributions reflect instances where the campaign is refunding money. This can happen for a variety of reasons. For instance, the Obama campaign had a policy of not accepting contributions from registered lobbyists and refunded money if they discover they have inadvertently violated this policy.

26. The full results for these samples are provided in the results appendix.

27. In unreported results, when counties are split at the median level of circulation, there are no statistically significant results for any of the three candidates. 


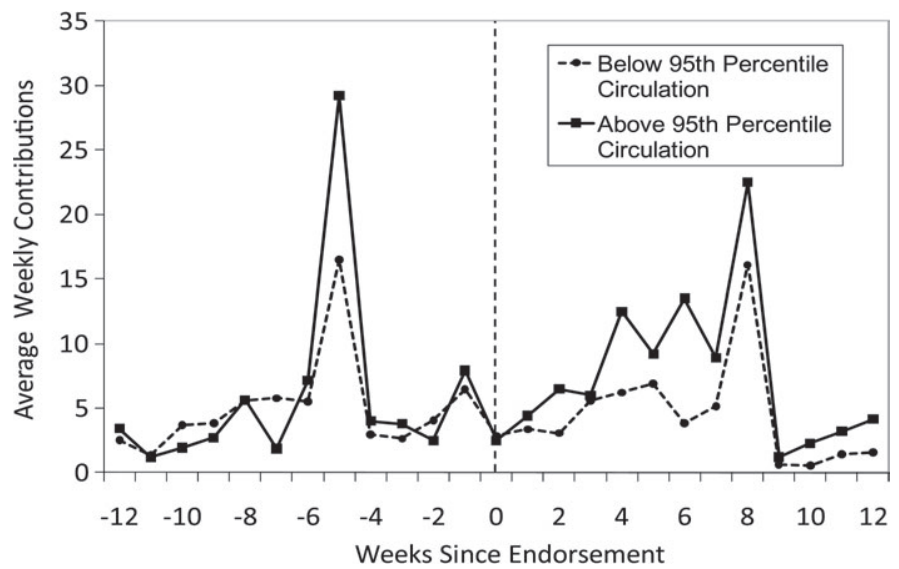

Figure 2. Average Weekly Obama Campaign Contributions by Percentile Circulation of Oprah Magazine.

counties above the 75 th percentile have approximately 0.28 more donors per week during the post-endorsement time period than the other counties. The effects for McCain and Romney are negative and statistically insignificant at conventional levels. Columns $4-6$ contain results for a specification with the treatment group defined as counties with Oprah Magazine circulation above the 95 th percentile. There is a positive effect for contributions to Obama, which is $63 \%$ larger than the estimates in column 1 and statistically significant at the 0.10 level. The marginal effect suggests that counties above the 95 th percentile have 0.46 more donors per week than the other counties. Similar to the results with a treatment group defined at the 75 th percentile, there is no statistically significant effect for either McCain or Romney.

Table 10. Fixed-Effects Negative Binomial Estimates of Campaign Contributions, May 2007 to August 2007

\begin{tabular}{|c|c|c|c|c|c|c|}
\hline & (1) Obama & (2) McCain & (3) Romney & (4) Obama & 5) McCain & (6) Romney \\
\hline $\begin{array}{l}\text { Postendorse, } \\
\text { above } 75 \text { th } \\
\text { percentile }\end{array}$ & $\begin{array}{l}0.282 \\
(0.131)^{\star \star}\end{array}$ & $\begin{array}{c}-0.122 \\
(0.120)\end{array}$ & $\begin{array}{c}-0.097 \\
(0.140)\end{array}$ & & & \\
\hline $\begin{array}{l}\text { Postendorse, } \\
\text { above 95th } \\
\text { percentile }\end{array}$ & & & & $\begin{array}{c}0.460 \\
(0.254)^{\star}\end{array}$ & $\begin{array}{c}-0.132 \\
(0.349)\end{array}$ & $\begin{array}{l}0.327 \\
(0.331)\end{array}$ \\
\hline $\begin{array}{l}\text { Posten } \\
\text { dorse }\end{array}$ & $\begin{array}{c}0.369 \\
(0.221)^{\star}\end{array}$ & $\begin{array}{l}0.404 \\
(0.153)^{\star \star}\end{array}$ & $\begin{array}{l}0.748 \\
(0.146)^{\star *}\end{array}$ & $\begin{array}{l}0.429 \\
(0.211)^{\star *}\end{array}$ & $\begin{array}{l}0.378 \\
(0.157)^{\star \star}\end{array}$ & $\begin{array}{l}0.715 \\
(0.140)^{\star \star \star}\end{array}$ \\
\hline$N$ & 299 & 299 & 299 & 299 & 299 & 299 \\
\hline$N \times T$ & 7774 & 7774 & 7774 & 7774 & 7774 & 7774 \\
\hline
\end{tabular}

Unreported covariates include a cubic weekly time trend and dummy variables for quarterly filing deadlines. Standard errors are in parentheses, and estimates are weighted using country-level adult population. $\mathrm{N} \times \mathrm{T}$ is the number of total county by week observations.

${ }^{*},{ }^{* *},{ }^{* \star}$ Significant at $0.1,0.05$, and 0.01 levels, respectively. 
This fixed-effects specification will accurately estimate the effect of the endorsement as long as the two groups of counties have similar pre-endorsement contribution trends. Table 11 contains the demographic statistics of counties split at the 95th percentile. The average weekly contributions before the endorsement are higher in the sample with lower levels of magazine circulation - with 10.97 average weekly contributions in the treatment group and 21.3 in the control group. Other demographics are similar apart from the treatment group having a lower fraction of Hispanics and higher fractions of whites and college graduates. Although the two groups appear similar prior to the endorsement, we conduct a falsification test to ensure that the results in Table 10 are not the result of differing trends between the two groups. We introduced a placebo endorsement on March 1, 2007, and limit the total sample to all weeks before the actual endorsement date-May 1, 2007. In Table 12, there is no statistically significant result for specifications with a treatment group when defined as counties above the 95th percentile. This suggests that the different pre-endorsement time trends are not driving the main results.

In many ways, this analysis of the effect on campaign contributions can be thought of as a further test for the presence of omitted variables driving the results in the previous section. The presence of an effect in this case, where we can see how contributions change within a country over time, strengthens the case that omitted variables are not driving the main result.

Table 11. County Demographic Statistics by Oprah Magazine Circulation

\begin{tabular}{lcc}
\hline & $\begin{array}{c}>95 \text { th percentile } \\
\text { Oprah circulation (\%) }\end{array}$ & $\begin{array}{c}<95 \text { th percentile } \\
\text { Oprah circulation (\%) }\end{array}$ \\
\hline Oprah circulation & 2.2 & 1.2 \\
per capita & 10.97 & 21.29 \\
Pre-endorsement & & \\
weekly contributions $(\$)$ & 49.1 & 48.0 \\
Male & 75.2 & 66.4 \\
White & 11.1 & 12.6 \\
Black & 6.1 & 13.4 \\
Hispanic & 49.6 & 53.6 \\
High school only & 39.8 & 27.6 \\
College graduate & 56.5 & 55.0 \\
Married & 12.8 & 12.6 \\
Divorced or separated & 5.2 & 6.9 \\
Widowed & 41.6 & 39.8 \\
40-64 years old & 12.9 & 16.5 \\
65+ years old & 4.7 & 5.9 \\
Male unemployment & 4.7 & 6.1 \\
Female unemployment & 617,549 & $1,148,441$ \\
Adult population $(n)$ & 65,932 & 54,609 \\
Median income $(\$)$ & 15 & 285 \\
$N$ & &
\end{tabular}


Table 12. Fixed-Effects Negative Binomial Estimates of Obama's Campaign Contributions, January 2007 to May 2007

\begin{tabular}{ll} 
Placeboendorse, above 95th percentile & $-0.027(0.301)$ \\
Placeboendorse & $0.805(0.301)^{\star \star}$ \\
$N$ & 299 \\
$N \times T$ & 4784 \\
\hline
\end{tabular}

Unreported covariates include a cubic weekly time trend and dummy variables for quarterly filing deadlines. Standard errors are in parentheses, and estimates are weighted using country-level adult population. $\mathrm{N} \times \mathrm{T}$ is the number of total county by week observations.

$*^{* * *, * \star}$ Significant at $0.1,0.05$, and 0.01 levels, respectively.

\section{The Magnitude of Winfrey's Endorsement}

These results provide strong evidence that Oprah Winfrey's endorsement of Barack Obama prior to the 2008 Democratic primary had an impact on his votes and on the overall number of voters. Understanding the magnitude of these effects is important. The Oprah Magazine regression results for primary elections and caucus elections are used to generate predictions of the vote share Obama would have received with and without Winfrey's endorsement. These are then used to predict county-level vote totals, and summed to provide an estimate of Winfrey's total effect on Obama's vote share, conditional on voting. We estimate that Winfrey's endorsement was responsible for $1,015,559$ votes for Obama. The 95\% confidence interval for this estimated effect is $423,123-1,596,995$. There are two important caveats for this estimate. The first is that this is the effect conditional on voting: it does not take into account any participation effect. The second is that this is the estimated effect for our sample of states, which does not include Texas, Michigan, North Dakota, Kansas, or Alaska. For the 45 states and the District of Columbia included in our sample, Obama received 278,966 more votes than Hillary Clinton. Given that the lower bound of the estimated impact of the endorsement is greater than this difference, the results suggest that Winfrey's endorsement was responsible for the difference in the popular vote between Obama and Clinton in our sample.

A similar approach is used to estimate the effect of Winfrey's endorsement on participation. We estimate that the endorsement was responsible for the increasing turnout in our sample by $2,196,300$, with a $95 \%$ confidence interval for this estimate between $1,673,183$ and $2,719,476$. This is a substantial impact, given there were $33,386,184$ votes in our sample. The lower bound of this estimate is strictly higher than the interval around our estimate for the number of additional votes Obama received, suggesting that the effect on participation is larger in magnitude than the effect on vote share. In combination, our estimates suggest that votes for other candidates increased as a result of the endorsement, although Obama's votes increased by far more. This suggests that a social multiplier affects participation or that the endorsement contained information about the importance of voting (or both).

Are the sizes of the estimated effects plausible? Oprah Winfrey is an exceptionally popular and influential celebrity. Every day, 8 million people 
watch her daily talk show, and it is estimated that 16 million people read each issue of Oprah Magazine. The estimated effect of the endorsement on vote share is therefore $12.5 \%$ of her daily audience and $6.3 \%$ of Oprah Magazine readers. Perhaps most significantly, $23 \%$ of Democrats reported that the endorsement would make them more likely to vote for Obama. The estimated effect represents only $2.5 \%$ of all votes cast by Democrats, far below the percentage who said their vote would be affected. Winfrey has already demonstrated an ability to influence the behavior of her fans in terms of their purchasing and philanthropic habits. Although voting is a distinctly different activity, the magnitudes of these endorsement effects are plausible in the context of these other behaviors.

\section{Conclusion}

The results of this study suggest that Oprah Winfrey's endorsement of Barack Obama prior to the 2008 Democratic presidential primary had statistically and politically significant effects on Obama's political outcomes. Winfrey's involvement increased the share of the vote and the campaign contributions received by Obama, as well as the overall level of voter participation. The estimated effect in our sample is larger than the difference in the popular vote totals at the end of the primary season.

To our knowledge, this is the first attempt to estimate the effect of a celebrity endorsement on political outcomes. The empirical results suggest that Obama enjoyed a higher-than-expected level of electoral success in areas with greater concentrations of Winfrey's fans. Questions of external validity exist on several dimensions. An obvious one is whether a similar effect could be found for other celebrities. It is clear that Winfrey is a celebrity of nearly unparalleled popularity. Therefore, this estimate likely serves as an upper bound of the potential effect of a celebrity endorsement. This does not mean that other endorsers would not have an effect but rather that such effects may be more difficult to detect.

A second dimension of concerns about the external validity of the results relates to the type of election. The empirical results of this article are focused on the dynamics of a primary election within one party. It is possible that the information provided by a celebrity endorsement, which is likely not directly related to policy, may be most important during a primary election, where candidates are nearly ideologically identical. In the case of a general election, where voters are more concerned with policy positions, it is not clear whether a celebrity endorsement would have the same influence.

It is important to consider the applicability of our results to endorsements by elected officials and special interest groups. Although the information conveyed by interest groups and elected officials would be quite different to that of celebrities, our finding that an endorsement can have empirically identifiable effects on voting behavior is at least suggestive that endorsements can convey information to voters in ways discussed in existing theoretical work. 
Finally, in determining the potential effects of endorsements, it is important to consider the role of indirect benefits. We find that Winfrey's endorsement increased Obama's campaign contributions, but it may have also attracted volunteers or increased other forms of support. Further work is required to assess the role of endorsements on these indirect benefits.

\section{References}

Adamowski, Thomas H. 2004. "Frank Sinatra: The Subject and His Music," 33 Journal of Popular Culture 1-11.

Agrawal, Jagdish, and Wager A. Kamakura. 1995. "The Economic Worth of Celebrity Endorsers: An Event Study Analysis," 59 Journal of Marketing 56-62.

Allison, Paul D., and Richard Waterman. 2002. "Fixed-Effects Negative Binomial Regression Models," 32 Sociological Methodology 247-65.

Andelman, David A. 2007. "Celebrity Power?"Forbes.com, October 17.

Arceneaux, Kevin, and Robin Kolodny. 2009. "Educating the Least Informed: Group Endorsements in a Grassroots Campaign," 53 American Journal of Political Science 755-70.

Butler, Richard, Benjamin Cowan, and Sebastian Nilsson. 2005. "From Obscurity to Bestseller: Examining the Impact of Oprah's Book Club Selections," 20 Publishing Research Quarterly $23-34$

Chiang, Chun-Fang, and Brian Knight. 2011. "Media Bias and Influence: Evidence from Newspaper Endorsements," 78 Review of Economic Studies 795-820.

Coate, Stephen. 2004. "Pareto Improving Campaign Finance Policy," 94 American Economic Review 628-55.

Davey, Monica. 2004. “As Quickly as Overnight, a Democratic Star Is Born,"New York Times , March 18, A20.

Duggan, Mark. 2001. "More Guns, More Crime," 109 Journal of Political Economy 1086-114.

Goldman, Lea. 2007. “The World's Most Powerful Celebrities,"Forbes.com June 17.

Grofman, Bernard, and Barbara Norrander. 1990. "Efficient Use of Reference Group Cues in Single Dimension," 64 Public Choice 213-27.

Grossman, Gene M., and Elhanan Helpman. 1999. "Competing for Endorsements," 89 American Economic Review 501-24.

Jolson-Colburn, Jeffrey. 2007. "The Hollywood Primaries,"Hollywood Today, January 31.

Kamins, M. A. 1989. "Celebrity and Non-celebrity Advertising in a Two Sided Context," 29 Journal of Advertising Research 34-42.

Knight, Brian, and Nathan Schiff. 2010. "Momentum and Social Learning in Presidential Primaries," 118 Journal of Political Economy 1110-50.

Levitt, Steven. 1994. "Using Repeat Challengers to Estimate the Effect of Campaign Spending on Election Outcomes in the U.S. House," 102 Journal of Political Economy 777-98.

Maddala, Gangadharrao S. 1983. Limited-Dependent and Qualitative Variables in Econometrics. Cambridge, UK: Cambridge University Press.

Mathur, Lynette Knowles, Ike Mathur, and Nanda Ragan. 1997. "The Wealth Effects Associated with a Celebrity Endorser: The Michael Jordan Phenomenon," 37 Journal of Advertising Research 67-73.

McDermott, Monika L. 2006. "Not for Members Only: Group Endorsements as Electoral Information Cues," 59 Political Research Quarterly 249-57.

Mediamark Research and Intelligence. 2007. Magazine Audience Estimates, Fall 2007 Revisited. New York, NY: Mediamark Research and Intelligence.

Morello, John A. 2001. Selling the President, 1920. Westport, CT: Praeger.

Ohanian, Roobina. 1991. "The Impact of Celebrity Spokespersons' Perceived Image on Consumers' Intention to Purchase," 31 Journal of Advertising Research 46-54.

Pew Research Center. 2007. The Oprah Factor and Campaign 2008: Do Political Endorsements Matter? Pew Research Center Report 357. Washington, DC: Pew Research Center. 
Prat, Andrea. 2002. "Campaign Advertising and Voter Welfare," 69 Review of Economic Studies 999-1017.

Rapoport, Ronald B., J. WalterStone, and Alan I. Abramowitz. 1991. "Do Endorsements Matter? Group Influence in the 1984 Democratic Caucuses," 85 American Political Science Review 193-203.

Scott, Megan K. 2007. “Will Oprah's Popularity Take a Hit?” Winnipeg Free Press, December 22, 7. Stratmann, Thomas. 2005. "Some Talk: Money in Politics. A (Partial) Review of the Literature," 124 Public Choice 135-56.

Wittman, Donald. 2007. "Candidate Quality, Pressure Group Endorsements, and the Nature of Political Advertising," 23 European Journal of Political Economy 360-78. 2009. "How Pressure Groups Activate Voters and Move Candidates Closer to the Median," 119 Economic Journal 1324-43.

Wolfinger, Raymond, and Stephen J. Rosenstone. 1980. Who Votes? New Haven, CT: Yale University Press.

Younge, Gary. 2008. "Feudal Democracy,"Nation, February 21. 